eCommons@AKU

April 2019

\title{
Survival and treatment outcomes of metaplastic breast carcinoma: Single tertiary care center experience in Pakistan
}

\author{
Zarka Samoon \\ Aga Khan University, zarka.samoon@aku.edu \\ Madiha Beg \\ Aga Khan University \\ Romana Idress \\ Aga Khan University, romana.idress@aku.edu \\ Adnan Jabbar \\ Aga Khan University, adnan.jabbar@aku.edu
}

Follow this and additional works at: https://ecommons.aku.edu/pakistan_fhs_mc_radiat_oncol

Part of the Oncology Commons, Radiation Medicine Commons, and the Radiology Commons

\section{Recommended Citation}

Samoon, Z., Beg, M., Idress, R., Jabbar, A. (2019). Survival and treatment outcomes of metaplastic breast carcinoma: Single tertiary care center experience in Pakistan. Indian Journal of Cancer, 56(2), 124-129.

Available at: https://ecommons.aku.edu/pakistan_fhs_mc_radiat_oncol/73 


\section{Abstract}

BACKGROUND: Metaplastic breast carcinoma $(\mathrm{MBC})$ is a rare disease with incidence of less than $1 \%$. MBC present with a larger tumor size, less number of nodes involved, mostly undifferentiated triple negative tumors. We aimed to determine progression-free and overall survival and reported hospital-based incidence of MBC.

MATERIAL AND METHODS: A retrospective closed Cohort study elicited data of 42 patients with MBC from January 2008 to December 2013 ; followed till August 2016. Kaplan-Meier method was applied to compute overall and progression-free survival analysis. Cox Proportional hazard ratios were computed to assess associations between survival and independent variables.

RESULTS: Hospital-based incidence of MBC was 1.92\% (42/2187), 95\% Cl [1.41-2.56]. The median age at tumor diagnosis was 54 years (range, 25-81 years). Thirty-nine (92.9\%) patients had Grade III tumor. The most common histopathology was squamous (69\%). The median tumor size was $4.5 \mathrm{~cm}$ (range, $0.8-17 \mathrm{~cm}$ ). Nineteen $(45.2 \%)$ patients had nodal involvement at diagnosis. Four patients $(9.5 \%)$ had metastatic disease at presentation. Hormone receptors were positive in 19 (45.2\%) patients. Her-2 neu receptor was positive in 9 (19\%) patients. Sixteen (38.1\%) patients had triple negative disease. Neoadjuvant and adjuvant chemotherapy was received by $10(31.25 \%)$ and 19 (45.2\%) patients respectively. Both median progression-free and overall survival was 38 months.

CONCLUSION: Five-year progression-free and overall survival was $79.5 \%$ and $76.3 \%$, respectively. We report better survival outcomes when compared to series described earlier despite our patient population presenting mostly with high grade, large tumors, and half of them exhibiting nodal and hormonal involvement.

Key Words: Breast, Kaplan- Meier analysis, metaplasia, neoadjuvant treatments, survival analysis

\section{Introduction}

Metaplastic breast carcinoma $(\mathrm{MBC})$ is a rare disease. Its incidence is said to be less than $1 \%$ amongst all breast cancer sub-types. ${ }^{[1]}$ In a study from India, its incidence was reported as $0.9 \% .^{[2]}$ They are a heterogeneous group of diseases having epithelial and mesenchymal components. Two to three different components may occur within the tumor at the same time. ${ }^{[3-9]}$ According to Wargotz et al. there are five variants of $\mathrm{MBC}$ which include matrix producing carcinomas, squamous cell carcinoma, spindle cell carcinoma, carcinosarcoma, and metaplastic carcinoma with osteoclastic giant cells..$^{[3-8]}$ Cumulative five-year survival rates of various subtypes ranges from $49 \%$ to $68 \%$. ${ }^{[3-7]}$ In comparison to invasive ductal carcinomas (IDC), MBC present with a larger tumor size, less number of nodes involved, mostly undifferentiated tumors, which are usually triple negative. ${ }^{[1,10,11]}$ When compared with IDC, patients with MBC have a shorter overall survival. ${ }^{[12,13]}$ In a study by Nelson et al. five-year disease specific survival was $78 \%$ in $\mathrm{MBC}$ as compared to $93 \%$ in those with IDC $(p<0.0001) .{ }^{[14]}$ There is no optimum treatment approach for management of MBC. Its management has been essentially similar to that of IDC. ${ }^{[15]}$

In this study, we reviewed a single center attempt to report outcome in terms of overall and progression-free survival of MBC patients. We analyzed several parameters such as menopausal status, tumor grade, stage, hormonal receptor, and Her 2 Neu status. This study reports the hospital-based incidence rate/proportion of $\mathrm{MBC}$ among all breast cancer subtypes. There was a lack of scientific literature from the

\begin{tabular}{|l|l|}
\multicolumn{3}{|c|}{ Access this article online } \\
\hline Quick Response Code: & Website: \\
\hline & www.indianjcancer.com \\
\cline { 2 - 3 } & DOI: \\
\hline & 10.4103/ijc.IJC_731_18 \\
\hline
\end{tabular}

developing countries regarding treatment options of MBC. Therefore, the study results may help in meeting the void.

\section{Material and Methods}

\section{Overview of study}

A retrospective close cohort study was designed to collect data. Data in this study were mainly collected from the Aga Khan University Hospital cancer registry and Health Information and Management System (HIMS) from January 2008 till December 2013. This system established in 2009 , is managed by the HIMS to identify all new cases. According to the Cancer Registry Regulations, this system identifies cancer in patients who report to our hospital for medical advice from all over Pakistan. The Aga Khan University Hospital (AKUH) is one of the main private cancer hospitals in the region. The follow up of patients with MBC was prospectively done until August 2016 regarding disease progression and survival.

\section{Study population}

All cases in the AKUH cancer registry and management system were identified by the coding system of the International Classification of Diseases for Oncology, $3^{\text {rd }}$ Revision (ICD-03), from the World Health Organization. ${ }^{[16]}$ In order to confirm the diagnosis of MBC and examine the changes on coding, we retrospectively collected and checked records of diagnosis and pathological reports of these cases. A review of the biopsy specimen was done by an experienced pathologist in order to confirm

This is an open access journal, and articles are distributed under the terms of the Creative Commons Attribution-NonCommercial-ShareAlike 4.0 License, which allows others to remix, tweak, and build upon the work non-commercially, as long as appropriate credit is given and the new creations are licensed under the identical terms.

For reprints contact: reprints@medknow.com

How to cite this article: Samoon Z, Beg M, Idress R, Jabbar AA. Survival and treatment outcomes of metaplastic breast carcinoma: Single tertiary care center experience in Pakistan. Indian J Cancer 2019;56:124-9. 
the diagnosis of MBC. A total of 42 patients who were diagnosed from August 2008 to December 2013 were recruited to calculate the progression-free survival and overall survival in this study. Non-probability purposive sampling methodology was employed to enroll patients for the study from the Health Information and Management System (HIMS). Patients aged 16 and above diagnosed with MBC and treated at the hospital were recruited. Patients were excluded if they were treated at another center, did not have a histologically confirmed diagnosis or sufficient staging information. Patients with bilateral disease were also excluded.

\section{Exposure variables under study}

The following variables were recorded at baseline for each patient including age, menopausal status, tumor grade, histological subtype, tumor size, nodal status, and metastatic involvement at presentation. Hormone receptor status including estrogen receptor (ER), progesterone receptor (PR) and Her-2 positivity were also documented. Type of surgery, chemotherapy received, be it neo-adjuvant, adjuvant or palliative, types of radiation received were also recorded. Development of locally recurrent disease and sites of distant metastasis were documented.

Estrogen receptor (ER), and progesterone receptor (PR) was defined according to Allred scoring as positive when the sum of proportion and intensity was two and above. ${ }^{[17]}$ Her- 2 positivity was defined as more than $10 \%$ strong complete membrane staining or positive with fluorescent in situ hybridization technique (FISH). ${ }^{[18]}$

\section{Outcome}

We examined two outcomes in terms of progression-free survival and overall survival. Progression-free survival (PFS) was calculated from the date of diagnosis until disease progression, death for any reason or the date of last contact. Overall survival (OS) was calculated from the date of diagnosis until death for any reason or the date of last contact. The follow up was prospectively done; PFS and OS were recorded by reviewing the charts and documenting last clinic visit. Hospital-based incidence rate/proportion of MBC was also computed. This was calculated by taking into account the number of newly diagnosed MBC patients and dividing them with all breast cancer subtypes that reported to the hospital from 2008 till 2013.

\section{Ethics approval}

The study protocol was initially accepted from the Ethical Review Committee of Aga Khan University Hospital, Karachi, Pakistan, with ERC \#3026-Med-ERC-14.

\section{Statistical analysis}

Data were entered into IBM SPSS Statistics for Windows, Version 19.0. Armonk, NY: IBM Corp. software and were transported and analyzed on STATA. Hospital-based incidence rate/proportion of $\mathrm{MBC}$ was computed. Mean and standard deviation was computed for continuous variables and proportions were reported for categorical variables. The purpose of the analysis was to report progression-free survival and overall survival. Survival analysis was applied in order to determine progression-free survival rate and overall survival rate of patients with MBC. A $P$ value of less than 0.05 was considered as statistically significant. Log rank test and Breslow test were assessed to check Proportional Hazard assumptions, $P$ value 0.049 and 0.061 , respectively. Therefore, the assumptions of survival analysis were met. Cox Proportional hazard ratios were computed to assess associations between survival and independent variables. The independent variables were menopausal status, tumor size, tumor grade, ER, PR, and Her 2 neu status, nodal involvement and disease stage. By applying non-parametric Kaplan-Meier survival curve technique, we estimated the PFS and OS rate.

\section{Results}

A total of 42 women were included from January 2008 until December 2013 in the study. They were followed up till August 2016. Their mean \pm SD age at diagnosis was $55.52 \pm 12.473$ years. The median age at tumor diagnosis was 54 years (range, $25-81$ years). The mean \pm SD follow up period was $39.77 \pm 24.19$ months. Their median follow-up period was 34 months (range, 0-94 months). There were 3 censored cases and 9 deaths. The data were censored under circumstances of being diagnosed at AKUH, but not seeking treatment from our center. One patient died because of myocardial infarction while on surveillance; seven died due to disease progression and one due to unknown cause. At data cut off, thirty patients were alive, three with disease and twenty-seven without disease.

Hospital-based incidence rate of $\mathrm{MBC}$ was $1.92 \%(42 / 2187), 95 \%$ CI [1.41-2.56].

\section{Patient characteristics}

Thirteen patients $(31 \%)$ were premenopausal, the remaining postmenopausal. Nineteen patients $(45.2 \%)$ were reported as hormone receptor positive and nine patients (19\%) as Her 2-neu positive disease. Sixteen (38.1\%) patients presented with triple negative disease. Squamous cell was the most common histology found in twenty-nine patients (69\%). The mean tumor size was $4.7 \mathrm{~cm} \pm 3.210 \mathrm{SD}$, (range, $0.8-17 \mathrm{~cm}$ ); $90 \%$ of patients presented with tumor size $>2 \mathrm{~cm}$. In this study, $19(45.2 \%)$ patients presented with nodal involvement at diagnosis. Even though majority (57.1\%) of the patients were diagnosed with stage two diseases, most (92.9\%) of them existed as Grade III tumor patients. Four patients $(9.5 \%)$ presented with metastatic disease at presentation, lung being the most common site involved, followed by bone and liver. All four of them had squamous histology. The baseline characteristics are given in Table 1.

\section{Curative treatment}

Neoadjuvant chemotherapy was received by 10 patients $(31.25 \%)$. Among these $8(80 \%)$ were of squamous histology. Anthracycline- and taxane-based chemotherapy was the most common $(70 \%)$ regimen used in this setting. Among these five $(50 \%)$ had a complete response.

Twenty-seven $(64.3 \%)$ patients underwent modified radical mastectomy, which was the most common surgery. Four $(9.5 \%)$ patients underwent simple mastectomy and sentinel lymph node biopsy (+/- axillary lymph node dissection) and 
Table 1: Baseline characteristics of patients with Metaplastic breast cancer patients

\begin{tabular}{|c|c|c|}
\hline Variable & Number of patients & Percentage \\
\hline Histological subtype & 42 & \\
\hline Squamous & 29 & 69 \\
\hline Spindle & 4 & 9.5 \\
\hline Carcinosarcoma & 3 & 7.1 \\
\hline Spindle cell and squamous & 2 & 4.8 \\
\hline Spindle cell and chondroid & 1 & 2.4 \\
\hline Squamous and chondromyxoid & 1 & 2.4 \\
\hline Subtype not specified & 2 & 4.8 \\
\hline \multicolumn{3}{|l|}{ Tumor size } \\
\hline $\mathrm{T} 1$ & 3 & 7.1 \\
\hline T2 & 28 & 66.7 \\
\hline T3 & 8 & 19 \\
\hline T4 & 3 & 7.1 \\
\hline \multicolumn{3}{|l|}{ Nodal status } \\
\hline No & 23 & 54.8 \\
\hline N1 & 12 & 28.6 \\
\hline N2 & 6 & 14.3 \\
\hline N3 & 1 & 2.4 \\
\hline \multicolumn{3}{|l|}{ Stage } \\
\hline Stage I & 3 & 7.1 \\
\hline Stage II & 24 & 57.1 \\
\hline Stage III & 10 & 23.8 \\
\hline Stage IV & 5 & 11.9 \\
\hline \multicolumn{3}{|l|}{ ER receptor* } \\
\hline Positive & 18 & 42.9 \\
\hline Negative & 23 & 54.8 \\
\hline Unknown & 1 & 2.4 \\
\hline \multicolumn{3}{|l|}{ PR receptor $\sim$} \\
\hline Positive & 14 & 33.3 \\
\hline Negative & 27 & 64.3 \\
\hline Unknown & 1 & 2.4 \\
\hline \multicolumn{3}{|l|}{ Her-2 neu receptor } \\
\hline Positive & 9 & 19 \\
\hline Negative & 31 & 73.8 \\
\hline Unknown & 3 & 7.2 \\
\hline \multicolumn{3}{|l|}{ Tumor grade } \\
\hline Grade I & 0 & 0 \\
\hline Grade II & 2 & 4.8 \\
\hline Grade III & 39 & 92.9 \\
\hline Unknown & 1 & 2.4 \\
\hline
\end{tabular}

*ER=Estrogen Receptor, $\sim P R=$ Progesterone Receptor

8 (19\%) underwent lumpectomy and sentinel lymph node biopsy (+/- axillary lymph node dissection).

Nineteen patients $(45.2 \%)$ received adjuvant chemotherapy among which $16(84.2 \%)$ were of squamous histology. Anthracycline- and taxane-based chemotherapy was again the most common $(57.9 \%)$ regimen used.

Twenty-eight $(66.6 \%)$ patients received adjuvant radiation out of which $16(38.1 \%)$ received radiation to the chest wall and axilla.

Fourteen $(33.33 \%)$ patients received adjuvant hormonal therapy among whom 9 (64.29\%) received anastrozole and $5(35.71 \%)$ received tamoxifen.
Table 2: Details of treatment in the curative setting

\begin{tabular}{|c|c|}
\hline Variable & Number of patients $(\%$ \\
\hline \multicolumn{2}{|l|}{ Neoadjuvant chemotherapy (NACT) } \\
\hline Received & $10(23.8)$ \\
\hline Not received & $32(76.2)$ \\
\hline \multicolumn{2}{|l|}{ Chemotherapy regimen } \\
\hline Anthracycline based & $2(20)$ \\
\hline Taxane based & $1(10)$ \\
\hline Anthracycline and taxane based & $7(70)$ \\
\hline \multicolumn{2}{|l|}{ Response to NACT } \\
\hline Complete response (CR) & $5(50)$ \\
\hline Partial response (PR) & $2(20)$ \\
\hline Stable disease (SD) & $2(20)$ \\
\hline Progressive disease (PD) & $1(10)$ \\
\hline \multicolumn{2}{|l|}{ NACT response } \\
\hline Responsive (CR + PR) & $7(70)$ \\
\hline Unresponsive (SD + PD) & $3(30)$ \\
\hline \multicolumn{2}{|l|}{ Type of surgery } \\
\hline $\mathrm{MRM}^{*}$ & 27 (64.3) \\
\hline$S M+S L N B / A L N D \S$ & $4(9.5)$ \\
\hline $\mathrm{BCS}+\mathrm{SLNB} / \mathrm{ALND} \sim$ & $8(19.0)$ \\
\hline \multicolumn{2}{|l|}{ Adjuvant Chemotherapy } \\
\hline Received & $19(45.2)$ \\
\hline Not received & $23(54.8)$ \\
\hline \multicolumn{2}{|l|}{ Chemotherapy regimen } \\
\hline Anthracycline based & $4(21.0)$ \\
\hline Taxane based & $1(5.3)$ \\
\hline Anthracycline and taxane based & $11(57.9)$ \\
\hline TCa & $3(15.8)$ \\
\hline \multicolumn{2}{|l|}{ Radiation } \\
\hline Received & $28(66.6)$ \\
\hline Not received & $14(33.3)$ \\
\hline \multicolumn{2}{|l|}{ Hormone treatment } \\
\hline Received & $17(40.5)$ \\
\hline Not received & $25(59.5)$ \\
\hline
\end{tabular}

*MRM=Modified Radical Mastectomy, § SM+SLNB/ALND=Simple Mastectomy and Sentinal Lymph Node Biopsy/Axillary Lymph Node Dissection, $\sim$ BCS + SLNB/ALND=Breast Conservation Surgery and Sentinal Lymph Node Biopsy/ Axillary Lymph Node Dissection, aTC=Taxotere and Cyclophosphamide

The details of treatment in the curative setting are given in Table 2.

\section{Palliative treatment}

At a median follow-up of 34 months (range, 0-94 months), metastatic disease was seen in 4 (9.52\%) [4/42] patients with lung being the most common site followed by bone and liver. Out of them, 1 died due to disease and 3 were lost to follow up. Progressive disease was observed in $9(24.32 \%)$ [9/37] patients. Out of them, 6 died due to disease, 2 were lost to follow up, and 1 was alive at data cutoff. Among the patients with progressive disease, lung was the most common site followed by bone. Palliative treatment modalities and survival outcomes are given in Table 3.

Most of the patients with progressive disease had hormone receptor negative disease $(77.7 \%)$. Three patients received hormonal treatment in the palliative setting. 

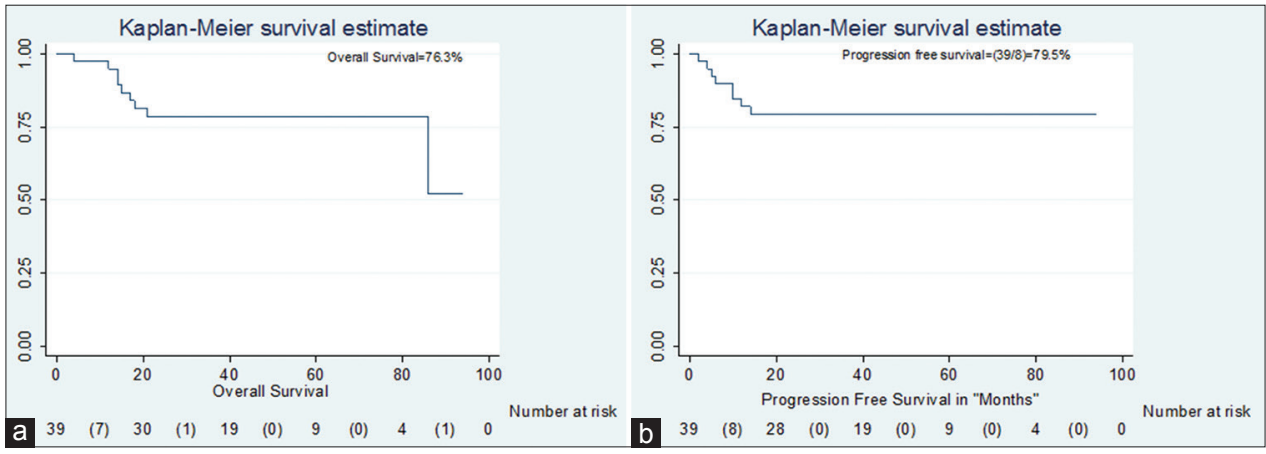

Figure 1: (a) Overall survival of Metaplastic breast cancer patients. (b) Progression-Free Survival of Metaplastic breast cancer patients

Table 3: Palliative treatment modalities and survival outcomes

\begin{tabular}{llc}
\hline Tumor histology & Palliative treatment & Overall survival (months) \\
\hline Squamous & Cisplatin and Gemcitabine & 22 \\
\hline Squamous & Temozolomide & 15 \\
\hline Squamous & $\begin{array}{l}\text { Anthracycline and cyclophosphamide-> Paclitaxel and transtuzumab } \\
\rightarrow \text { Vinorelbine and transtuzumab } \rightarrow \text { Vinorelbine and lapatinib } \rightarrow \\
\text { Lapatinib and Capecitabine } \rightarrow \text { Everolimus and Exemestane }\end{array}$ & 22 \\
\hline Spindle cell & Docetaxel and Cyclophosphamide & 14 \\
\hline Spindle cell & Paclitaxel $\rightarrow$ Capecitabine & 21 \\
\hline Spindle cell & Exemestane & 18 \\
\hline Carcinosarcoma & Docetaxel & 30 \\
\hline
\end{tabular}

Table 4: Overall survival according to independent variables

\begin{tabular}{|c|c|c|}
\hline & Number at risk & Overall Survival (\%) \\
\hline \multicolumn{3}{|l|}{ Age } \\
\hline$<50$ & 9 & 88.9 \\
\hline$>50$ & 30 & 76.7 \\
\hline \multicolumn{3}{|l|}{ Her 2} \\
\hline Positive & 7 & 78.1 \\
\hline Negative & 32 & 78.1 \\
\hline \multicolumn{3}{|l|}{ Stage } \\
\hline Stage I & 3 & 66.7 \\
\hline Stage II & 23 & 87 \\
\hline Stage III & 10 & 70 \\
\hline Stage IV & 3 & 66.7 \\
\hline \multicolumn{3}{|l|}{ Tumor size } \\
\hline $\mathrm{T} 1(<2 \mathrm{~cm})$ & 3 & 66.7 \\
\hline $\mathrm{T} 2(>2-5)$ & 27 & 88.9 \\
\hline T3 $(>5)$ & 7 & 42.9 \\
\hline T4 & 2 & 100 \\
\hline \multicolumn{3}{|l|}{$\overline{E R^{*}}$} \\
\hline Positive & 18 & 83.3 \\
\hline Negative & 20 & 75 \\
\hline \multicolumn{3}{|l|}{$\overline{\mathrm{PR} \sim}$} \\
\hline Positive & 14 & 92.2 \\
\hline Negative & 24 & 70.8 \\
\hline
\end{tabular}

\section{Survival analysis}

By applying non-parametric Kaplan-Meier survival curve technique, we estimated the five-year PFS rate as $79.5 \%$ and five year OS rate as $76.3 \%$ [Figure la and b]. The median progression-free survival (PFS) and overall survival (OS) was 38 months (range, 2-94 months) and 38 months (range, 4-94 months), respectively. The censored patients were Indian Journal of Cancer | Volume 56 | Issue 2 | April-June 2019 excluded from the survival analysis. The overall survival based on independent variables is given in Table 4 .

The two primary endpoints were PFS and OS among patients diagnosed as MBC. Factors associated with better progression-free and overall survival were tumor grade and menopausal status. When stratified based on Her-2 neu status, tumor size, nodal size, tumor stage, or progesterone receptor status, neither of these factors were associated with any improvement in progression-free or overall survival. Adjusted analysis of MBC patient's survival is given in Table 5 .

\section{Discussion}

$\mathrm{MBC}$ is a rare and heterogeneous group of diseases. ${ }^{[1,12,19]}$ In our study it accounted for $1.92 \%(42 / 2187)$ of all invasive breast cancers. The median age at presentation varies between 45 to 61 years. ${ }^{[1,12,13,19,20]}$ Our study reports a median age of $\mathbf{5 5 . 5}$ years, which is in concordance with published literature. There is a variability among the median tumor size ranging from 3.4-5.7 $\mathrm{cm} .{ }^{[12,19,21]}$ The median tumor size in our study was $4.5 \mathrm{~cm}$ supporting international data of these tumors presenting with a large tumor size. It is usually associated with negative nodal involvement with studies reporting between 4.4 to $35 \%$ lymph node metastasis. ${ }^{[12,22,23]}$ This is in contrast to our series in which $53.1 \%$ patients had lymph nodes involved. However, in a similar Turkish study, $63.4 \%$ patients had axillary lymph nodes involved ${ }^{[19]}$ suggesting that the Asian population had a propensity to involvement of lymph nodes. Leyrer et al. reported $35 \%$ rate of distant metastasis; ${ }^{[20]}$ our study reported $24.32 \%$.

The surgical approach has been comparative to patients with IDC, with breast conserving therapy showing similar overall survival to mastectomy in the appropriate patients. ${ }^{[24]}$ 
About $64.3 \%$ of our patients underwent modified radical mastectomy bearing in mind that $90 \%$ patients had a tumor size of more than $2 \mathrm{~cm}$.

Standard chemotherapy regimens used for patients with IDC have little effect in women with MBC. ${ }^{[25]}$ In a study by Rayson et al. 9 patients received adjuvant chemotherapy, among which 7 developed disease recurrence $(77.7 \%){ }^{[12]}$ In our series 19 patients received adjuvant chemotherapy and one developed disease recurrence $(5.2 \%)$. We report $70 \%$ (50\% PCR, 20\% PR) response to neoadjuvant chemotherapy which is way higher than data reported in the past. In a study from Cleveland, 39\% patients had a pCR. ${ }^{[20]}$ In a Turkish study, none of the patients had a pCR, and $6.2 \%$ partial response. ${ }^{[26]}$ Outcomes are better in patients who achieve pCR. In our study none of the patients with pCR developed metastatic disease versus $60 \%(3 / 5)$ in those without pCR. The percentage of metastatic disease was $11 \%$ vs. $50 \%$ in those with and without pCR in a similar study. ${ }^{[20]}$

Historically majority (71\%) of $\mathrm{MBC}$ cases are triple negative. ${ }^{[11,22]}$ Hence, hormonal therapy largely has no role in these patients. ${ }^{[10]}$ In our series a total of $38.1 \%$ patients were found to have triple negative disease. In a study by Gultekin et al. ${ }^{[22]}$ none of the patients were her 2-neu receptor positive; however, $9.4 \%$ of our patients were Her-2 neu receptor positive. Estrogen and progesterone receptor positivity has been reported up tol1.3\% and 10.4\% respectively by Pezzi et al. ${ }^{[1]}$ In our patients $45.2 \%$ were ER and PR receptor positive. Bae et al. report giving hormonal treatment to three patients, with no recurrence in the follow up period. ${ }^{[10]}$ Rayson et al. gave palliative tamoxifen to 4 patients, but none of them reported any response. ${ }^{[12]}$ Thirteen patients received adjuvant hormonal treatment

Table 5: Adjusted analysis of Metaplastic breast cancer patient's survival

\begin{tabular}{|c|c|c|c|c|c|c|}
\hline \multirow[t]{2}{*}{ Characteristics } & \multicolumn{3}{|c|}{$\begin{array}{c}\text { Overall Survival } \\
\text { Analysis }\end{array}$} & \multicolumn{3}{|c|}{$\begin{array}{l}\text { Progression-Free } \\
\text { Survival Analysis }\end{array}$} \\
\hline & $\mathrm{HR}^{*}$ & $95 \% \mathrm{ClO}$ & $P$ & $\mathrm{HR}^{*}$ & $95 \% \mathrm{Cl}, 0$ & $P$ \\
\hline Her2 Neu & 1.8 & $0.22-15.14$ & 0.6 & 1.6 & $0.197-13.04$ & 0.7 \\
\hline Tumor size & 1.5 & $0.54-39.14$ & 0.5 & 1.9 & $0.57-6.5$ & 0.3 \\
\hline Stage & 1.46 & $0.62-3.49$ & 0.4 & 1.4 & $0.548-3.46$ & 0.5 \\
\hline Nodal Stage & 1.54 & $0.83-2.89$ & 0.2 & 1.3 & $0.64-2.78$ & 0.4 \\
\hline Grade & 0.3025 & $0.06-1.61$ & 0.2 & 0.4 & $0.044-2.95$ & 0.3 \\
\hline Menupause & 0.8175 & $0.17-3.94$ & 0.8 & 1.0 & $0.199-4.91$ & 1.0 \\
\hline Progesterone receptor & 4.68 & $0.58-38.18$ & 0.1 & 4.6 & $0.56-37.21$ & 0.2 \\
\hline
\end{tabular}

* $\mathrm{HR}=$ Hazard Ratio, $\mathrm{aCl}=$ Confidence Interval among which one patient developed progressive disease. Only one patient in this study received palliative hormonal treatment and did not have progression till 18 months of follow up. She however was lost to follow up later.

The five-year PFS from International data is reported between $30 \%$ and $69 \% .{ }^{[23,27,28]}$ We report a five-year PFS of $79.5 \%$. Similarly, various studies report five-year OS between $65 \%$ and $69 \% .^{[20,23,27,28]}$ In our study the five-year OS was $76.3 \%$. Both the PFS and OS of our patient population are higher than survivals reported from the West. However, the higher survival is similar to that reported from three Asian countries, namely of patients reported from Turkey by Gultekin et al. (76\% and $80 \%$ five-year PFS and OS, respectively), from China by Zhang et al. (67.9\% and $78.7 \%$ five-year PFS and OS, respectively) and from Korea by Bae et al. (78.1\% three-year PFS). ${ }^{[10,11,22]}$ Comparison of previous literature in terms of PFS and OS of MBC patients with our study is given in Table 6 .

MBC is associated with high potential of metastatic disease with lungs being the most common site involved. ${ }^{[12,19]}$ In our study nine $(9 / 42 ; 21.42 \%)$ patients developed metastatic disease, out of which six had lung involved. The median overall survival after disease progression was 21 months which is higher in comparison to previous study. ${ }^{[12]}$

In a study by Rayson et al. women younger than 60 years and with prior history of estrogen use were associated with decreased disease-free survival. ${ }^{[12]}$ In contrast, women younger than 50 had better survival in our series. Negative nodal involvement was associated with better outcomes in a study reported by Dave et al. ${ }^{[24]}$. No such association was found in our study. In a study by Leyrer et al., there was no difference in outcomes based on histologic subtype. ${ }^{[20]}$ Squamous cell histology was the most common subtype in our series. However, outcome analysis could not be performed comparing various subtypes as the proportion of these was very small.

Unanswered questions and future directions for research Multiple studies prove that MBC is said to have the worst prognosis among all cancer subtypes. There have been case reports of use of doxorubicin, ifosfamide, and etoposide in sarcomatoid and carcinosarcoma variant of MBC. ${ }^{[29,30]}$ However, clinical trials are required to explore these potential new therapies.

\section{Strengths of study}

To the best of our knowledge, this is the first single center study reported at a tertiary care hospital from our

Table 6: Comparison of previous literature in terms of five-year progression-free and overall survival of MBC patients

\begin{tabular}{|c|c|c|c|c|c|}
\hline Author & Country & Year of publication & Number of cases & Progression-Free Survival & Overall Survival \\
\hline Fayaz D et al. & Kuwait & 2017 & 31 & $50 \%, 0$ & $69 \%$ \\
\hline Zein E et al. & USA & 2017 & 46 & $30 \% \mathrm{x}$ & $65.30 \%$ \\
\hline Leyrer B et al. & USA & 2017 & 113 & * & $69 \%$ \\
\hline Esbah et al. & Turkey & 2012 & 14 & $33 \% \S$ & $56 \% \S$ \\
\hline Cimino-Mathews et al. & USA & 2016 & 45 & $64 \%$ & $69 \%$ \\
\hline Samoon et al. & Pakistan & 2018 & 42 & $79.50 \%$ & $76.30 \%$ \\
\hline
\end{tabular}

*Progression-Free Survival unreported by Authors. aFive-year Disease-Free Survival. ${ }^{\circledR}$ Three-year Survival 
region. We report $70 \%(50 \% \mathrm{PCR}, 20 \% \mathrm{PR})$ response to neoadjuvant chemotherapy, which is way higher than the data reported in the past.

\section{Limitations of study}

There were several limitations of the study. This was a retrospective study with a small sample. Some patients were lost to follow up and data regarding their treatment was not available.

\section{Conclusion}

In conclusion, $\mathrm{MBC}$ is a rare and aggressive variant of breast cancer. Five-year progression-free and overall survival was $79.5 \%$ and $76.3 \%$, respectively. We report better survival outcomes when compared to series described earlier despite our patient population presenting mostly with high grade, large tumors, and half of them exhibiting nodal and hormonal involvement. Literature exploring molecular targets and clinical trial exploring tumor-specific therapies is required to improve disease prognosis.

Financial support and sponsorship

Nil.

\section{Conflicts of interest}

There are no conflicts of interest.

\section{References}

1. Pezzi CM, Patel-Parekh L, Cole K, Franko J, Klimberg VS, Bland K. Characteristics and treatment of metaplastic breast cancer: Analysis of 892 cases from the National Cancer Data Base. Ann Surg Oncol 2007; 14:166-73.

2. Saxena S, Rekhi B, Bansal A, Bagga A, Chintamani, Murthy NS. Clinico-morphological patterns of breast cancer including family history in a New Delhi hospital, India-A cross-sectional study. World J Surg Oncol 2005;3:67.

3. Wargotz ES, Norris HJ. Metaplastic carcinomas of the breast. III. Carcinosarcoma. Cancer 1989;64:1490-9.

4. Wargotz ES, Deos PH, Norris HJ. Metaplastic carcinomas of the breast. II. Spindle cell carcinoma. Hum Pathol 1989;20:732-40.

5. Wargotz ES, Norris HJ. Metaplastic carcinomas of the breast. I. Matrix-producing carcinoma. Hum Pathol 1989;20:628-35.

6. Wargotz ES, Norris HJ. Metaplastic carcinomas of the breast: V. Metaplastic carcinoma with osteoclastic giant cells. Hum Pathol 1990;21:1142-50.

7. Wargotz ES, Norris HJ. Metaplastic carcinomas of the breast. IV. Squamous cell carcinoma of ductal origin. Cancer 1990;65:272-6.

8. Wargotz ES, Norris HJ. Metaplastic carcinomas and sarcomas of the breast. Am J Clin Pathol 1991;96:781.

9. Oberman HA. Metaplastic carcinoma of the breast. A clinicopathologic study of 29 patients. Am J Surg Pathol 1987; 11:918-29.

10. Bae SY, Lee SK, Koo MY, Hur SM, Choi MY, Cho DH, et al. The prognoses of metaplastic breast cancer patients compared to those of triple-negative breast cancer patients. Breast Cancer Res Treat 2011;126:471-8.

11. Zhang Y, Lv F, Yang Y, Qian X, Lang R, Fan Y, et al. Clinicopathological features and prognosis of metaplastic breast carcinoma: Experience of a major chinese cancer center. PLoS One 2015; 10:e0131409.
12. Rayson D, Adjei AA, Suman VJ, Wold LE, Ingle JN. Metaplastic breast cancer: Prognosis and response to systemic therapy. Ann Oncol 1999; 10:413-9.

13. Luini A, Aguilar M, Gatti G, Fasani R, Botteri E, Brito JA, et al. Metaplastic carcinoma of the breast, an unusual disease with worse prognosis: The experience of the European Institute of Oncology and review of the literature. Breast Cancer Res Treat 2007;101:349-53.

14. Nelson RA, Guye ML, Luu T, Lai LL. Survival outcomes of metaplastic breast cancer patients: Results from a US population-based analysis. Ann Surg Oncol 2015;22:24-31.

15. Gradishar WJ, Anderson BO, Balassanian R, Blair SL, Burstein HJ, Cyr A, et al. Invasive breast cancer version 1.2016, NCCN clinical practice guidelines in oncology. J Natl Compr Canc Netw 2016;14:324-54.

16. World Health Organization. International Statistical Classification of Diseases and Related Health Problem. 10 ${ }^{\text {th }}$ revision. Geneva: World Health Organization; 1992.

17. Harvey JM, Clark GM, Osborne CK, Allred DC. Estrogen receptor status by immunohistochemistry is superior to the ligand-binding assay for predicting response to adjuvant endocrine therapy in breast cancer. J Clin Oncol 1999; 17:1474-81.

18. Wolff AC, Hammond ME, Schwartz JN, Hagerty KL, Allred DC, Cote RJ, et al. American Society of Clinical Oncology/College of American Pathologists guideline recommendations for human epidermal growth factor receptor 2 testing in breast cancer. Arch Pathol Lab Med 2007; 131:18-43.

19. Esbah O, Turkoz FP, Turker I, Durnali A, Ekinci AS, Bal O, et al. Metaplastic breast carcinoma: Case series and review of the literature. Asian Pac J Cancer Prev 2012; 13:4645-9.

20. Leyrer CM, Berriochoa CA, Agrawal S, Donaldson A, Calhoun BC, Shah C, et al. Predictive factors on outcomes in metaplastic breast cancer. Breast Cancer Res Treat 2017; 165:499-504.

21. Song Y, Liu X, Zhang G, Song H, Ren Y, He X, et al. Unique clinicopathological features of metaplastic breast carcinoma compared with invasive ductal carcinoma and poor prognostic indicators. World J Surg Oncol 2013;11:129.

22. Gultekin M, Eren G, Babacan T, Yildiz F, Altundag K, Guler N, et al. Metaplastic breast carcinoma: A heterogeneous disease. Asian Pac J Cancer Prev 2014; 15:2851-6.

23. Cimino-Mathews A, Verma S, Figueroa-Magalhaes MC, Jeter SC, Zhang Z, Argani P, et al. A Clinicopathologic analysis of 45 patients with metaplastic breast carcinoma. Am J Clin Pathol 2016; 145:365-72.

24. Dave G, Cosmatos H, Do T, Lodin K, Varshney D. Metaplastic carcinoma of the breast: A retrospective review. Int J Radiat Oncol Biol Phys 2006;64:771-5.

25. Tzanninis IG, Kotteas EA, Ntanasis-Stathopoulos I, Kontogianni P, Fotopoulos G. Management and outcomes in metaplastic breast cancer. Clin Breast Cancer 2016 Dec; 16:437-43.

26. Aydiner A, Sen F, Tambas M, Ciftci R, Eralp Y, Saip P, et al. Metaplastic breast carcinoma versus triple-negative breast cancer: Survival and response to treatment. Medicine (Baltimore) 2015;94:e2341.

27. Fayaz S, Demian GA, Eissa HE, Amanguno H, Abuzalouf S. Metaplastic breast carcinoma: Analysis of 31 cases from a single institute. J Egypt Natl Canc Inst 2017;29:141-5.

28. El Zein D, Hughes M, Kumar S, Peng X, Oyasiji T, Jabbour H, et al. Metaplastic carcinoma of the breast is more aggressive than triple-negative breast cancer: A study from a single institution and review of literature. Clin Breast Cancer 2017; 17:382-91.

29. Hennessy BT, Giordano S, Broglio K, Duan Z, Trent J, Buchholz TA, et al. Biphasic metaplastic sarcomatoid carcinoma of the breast. Ann Oncol 2006; 17:605-13.

30. Brown-Glaberman U, Graham A, Stopeck A. A case of metaplastic carcinoma of the breast responsive to chemotherapy with Ifosfamide and Etoposide: Improved antitumor response by targeting sarcomatous features. Breast J 2010;16:663-5. 